of the Physical Society ; that with a few modifications it could deal with all the more important physical papers annually published in this country; and that such centralisation is very desiral le. Such modifications I beg to suggest are the follon. ing :-(I) Let mathematical papers, i.e., those which consist of problems in mixed mathematics rather than pure physics, be offered to the Phil. Mag., publishing the conclusions, with a reproduction of any resulting diagram, in brief abstract in the journal. (2) Let papers be invited not only for reading during the winter season, but for publication at intervals throughout the sear, whenever enough matter has been collected to fill a number, as is done in many other publications. (3) Let selections be made from these for reading, on the grounds $[a]$ of scientific importance, [b] suilability for discussion, [c] experimental demonstration. (4) Reprint in abstract, or occasionally in full, papers read before other societies (excepting, of course, the Royal Society).

I feel that some apology is due for making these suggestions elsewhere than at an annual general meeting of the Physical Society, but the attendance at the meetings is no measure of the important work which this society does in the publication of physical papers, and as these suggestions arise directly out of the discussion which has arisen in your columns, they may perhaps not be out of place there.

28, Victoria Street, Westminster.

\section{The Definition of "Heredity."}

WHEN all the world is ringing with the words "heredity" and "inheritance," it is natural to feel some surprise and amazement on hearing from even so high an authority as Dr. Hurst that they are expressive of nothing but the incoherence of ideas emanating from confused brains. Perhaps as a student of Darwinism I may be allowed a little suace in your columns to suggest that there is an alternative view to that held by Dr. Hurst.

His position I understand to be this : No force of any kind except natural selection is at work to preserve the form of organisms from alteration. Does he mean to confine the application of this statement to organisms existing under stable conditions, or would it have equal force in the probably numerous cases where temporary changes in circumstances occur? Now it cannot be denied that there is some factor of considerable power controlling the variations of species from the normal type; but that it is a natural selection, as ordinarily understood, seems to me to be at least open to discussion. If, without the action of natural selection all species are liable to react to any change in their environment, there is no reason against and very great probability in favour of many species having been destroyed by the advent of new conditions followed by the substitution of new forms quite ill-adapted to the old conditions. What would then be likely to happen should the original circumstances return? Two alternatives are possible under Dr. Hurst's view. Either the form resulting from the first change must be lost, or it must again become modified; but the chances are infinite against any approximation to the original organism being reached unless there be some tendency towards a return to former types.

If we adhere to the opinion that "heredity is something more than mere family likene:s," and not quite comparable to the "tendency of all weathercocks to point to the south-west," we are at once freed from the difficulty, and can see how a species might outlive many temporary changes in the form of influences to which it might be subjected. In order that species may be modified to suit new permanent surroundings it is obviously unnecessary that the variations arising among the individuals shall be very frequent, and, when organisation and environment are in agreement, it is equally obvious that the fewer the departures from the normal type the better will it be for the species. If, then, the tendency is strong in all organisms to conform to an ancestral type, whenever ihere is a merely temporary change of environment the chances of some at least of the individuals leaving unmodified descendants, when the old conditions reassert themselves, is vastly increased ; and if mean. while some other individual families have become somewhat modified, then the number of species in existence may also have been increased. Of course I am supposing that the period during which abnormal conditions of life remain in force shall not extend sufficiently to allow all the unmodified individuals to be eliminated by the action of natural selection.

If I have been successful in my argument, I think it will be clear that the force which I should designate by the term "heredity" cannot be described as a tendency fostered by natural selection; for, while any influence it may exert antagonistic to the development and continuance of species will be counteracted by natural selection, the bent fits it may confer are almost entirely prospective, and therefore do not fall within the range of the force which tends to preservo favourable variations.

I conceive that the definition of the word " heredity" should be-the tendency, more or less strong according to the age of the species, to follow certain types, exhibited by all organisms, and that it is no mere abstract idea devoid of objective existence, but a force the importance of which we are not yet able to fully grasp.

In conclusion I should like to mention a point with regard to the case of Saturnia which has, I think, been overlooked. What has really been proved is simply the fact that the insect is extremely susceptible to modification by change of food. If some entirely new food-plant, if possible chosen from an entirely different order, could be found as a substitute for either species of Juglans, and the result were carefully $и$ atched, the experiment could not fail to be instructive, I will not say conclusive.

Rochdale, August 19. T. SPENCER SMITHSON

\section{Sexual Colouration of Birds.}

THE recent controversy in your columns with regard to the non-inheritance of acquired characters opens up the question whether the principle of natural selection operates universally in the animal kingdom, or whether we must involve other causes to supplement it. In Dr. Hurst's letter of August 17 (p. 368) is a sentence which seems to embody what has generally been understood as Darwinisn: "If anything has ever been rendered certain in biology by prolonged experiment and observation, it is the fact that specific characters are maintained constant by selection, and that alone." But how does this agree with Dr. Wallace's theory of accessory plumes? This theory he himself thus expresses ("Darwinism," p. 293): "The fact that they have been developed to such an extent in a few species is an indication of such perfect adaptation to the conditions of existence, such complete success in the battle for life, that there is in the aduit male, at all events, a surplus of strength, vitality, and growth-power which is able to expand itself in this way without injury." Here we have two entirely different views of what is meant by the struggle for existence. According to Dr. Hurst it is incessant ; let its operation cease, and the characters of the species become speedily obliterated. According to Dr. Wallace a victorious species may leave the arena, and rest upon its laurels. But if natural selection ceases to work in this field, why not in others? The colours, it is true, may be due merely to waste products turned to account, but the annual gronth of the peacock's plumes-often nearly five feet in length-must require a great expenditure of vital force.

In Brown's "Thier-reich" it is stated that even in ordinary cases moulting is not unaccompanied with danger to the bird. And this is not all: the secondary wing feathers of the argus pheasant are developed to such an extent that they are said "almost entirely to deprive the bird of flight" ("Descent of Man," vol. ii. p. 97). The theory by which Darwin himself accounted for these phenomena, viz. that the female selected the most briliiantly coloured male as her partner, explained the facts, but failed for want of sufficient evidence that any such selection took place. I cannot think that the two forms of sexual selection, by battle and by female preference, conflict, since the hen bird might well admire the combination of fine plumes and war. like prowess.

There is, besides, Mr. Stolzmann's theory that it is to the advantage of the species that the number of males should be kept down, since hachelor males persecute the hen bird upon the nest. This assumes what is not well proved, that males largely outnumber females. But a very large proportion of the species in which the cock-bird is highly decorated are pulygamous, and in these cases the number of males is obviously excessive. Mr. Stolzmann's theory in no way conflicts with Darwin's, but rather supplements it. Moreover, it is hardly more than an extension of Dr. Wallace's view that the dullness of the female's plumage is due to her need of protection, which in the case of the male is less necessary. Both Darwin's theory and Mr. Stolzmann's require further evidence, but they tach have the merit of suggesting a cause for the constancy of the same plumage through successive generations.

Scourie, Lavig, N.B., August 24. 